\title{
National Hockey League Reported Concussions, 1986-87 to 2001-02
}

\author{
R.A. Wennberg, C.H. Tator
}

\begin{abstract}
Objectives: To examine the longitudinal media reported rate of concussions in the National Hockey League (NHL) over the period 1986-87 to 2001-02. Methods: All injury reports published in the weekly sports newspaper The Hockey News for the 16 seasons 1986-87 through 200102 were reviewed for reported concussions. The Hockey News reports are based on weekly injury reports released by the NHL, which derive from reports submitted to the league by individual team offices. Results: Adjusted for changes in the number of teams and games per season over the 16 year study period, and expressed as: number of concussions per 1000 games, results by season (starting with 198687) were $4,8,7,7,5,5,7,7,6,8,13,20,30,27,30,25$. Comparing each season with the prior season, significant increases were reported in 1997-98 and 1998-99 ( $<<0.05$ and 0.025 , respectively), with no change since 1998-99. Conclusions: The reported concussion rate in the NHL during the last five years is more than triple that of the previous decade. Bigger, faster players, new equipment and harder boards and glass have all theoretically increased the risk of concussion in the NHL in recent years. However, the abrupt increase and subsequent plateau in concussion rate since 1997 suggests that increased recognition and reporting may be primarily responsible for the apparent increase in incidence.
\end{abstract}

RÉSUMÉ: Les commotions cérébrales rapportées dans la Ligue nationale de hockey entre 1986-87 et 2001-02. Objectifs: Examiner le taux longitudinal de commotions cérébrales rapporté par les media de 1986-87 à 2001-02 dans la Ligue nationale de hockey (LNH). Méthodes: Tous les rapports de blessures publiés dans l'hebdomadaire sportif The Hockey News pendant 16 saisons consécutives, soit de 1986-87 à 2001-02 inclusivement, ont été revus pour identifier les cas de commotions cérébrales. Les rapports publiés dans cet hebdomadaire sont basés sur les rapports hebdomadaires de blessures fournis par la LNH et venant de rapports soumis à la ligue par le bureau de chaque équipe. Résultats: Les résultats ont été ajustés pour les changements du nombre d'équipes et de parties par saison pendant la durée de l'étude. Ils sont exprimés en nombre de commotions par 1000 parties et par saison à partir de 1986-87: 4, 8, $7,7,5,5,7,7,6,8,13,20,30,27,30,25$. En comparant chaque saison avec la précédente, on constate une augmentation significative des cas rapportés en 1997-98 et 1998-99 ( $\mathrm{p}<0,05$ et 0,025 respectivement). Aucun changement n'a été constaté depuis 1998-99. Conclusions: Le taux de commotions cérébrales rapporté dans la LNH dans les cinq dernières années est plus du triple de celui de la décennie précédente. Des joueurs plus costauds, plus rapides, un équipement nouveau et des rampes et des vitres de protection plus dures ont augmenté, du moins théoriquement, le risque de commotion cérébrale dans la LNH dans les dernières années. Cependant, le fait qu'on constate une augmentation subite puis un plateau dans le taux de commotions cérébrales depuis 1997 suggère qu'il est possible que l'augmentation de l'incidence soit due à ce que cette pathologie est plus souvent reconnue et rapportée.

Can. J. Neurol. Sci. 2003; 30: 206-209

There has been an increase in awareness of sports-related concussions in recent years. Whether this has arisen because of an increase in the incidence of injury or an increase in the recognition of a longstanding problem is unclear. Ice hockey, especially at the professional level, is one of the sports most commonly implicated in the discourse surrounding sports-related concussion. Nevertheless, there is scant published longitudinal data on concussion rates in hockey at any level, and none from the professional National Hockey League (NHL). The current NHL concussion program, which started collecting data in 1997, has found the number of concussions to be increasing in recent years, ${ }^{1}$ although data from this study have not been (and may never be) formally published. Data ownership issues, cloaked in references to medical confidentiality, have thus far prevented formal publication of epidemiologic injury data from North American professional sports leagues. ${ }^{2}$

Media reports of injuries in professional sports, however,

From the Divisions of Neurology (RAW) and Neurosurgery (CHT), University Health Network, Toronto Western Hospital, University of Toronto, Toronto, ON Canada. ReCEIVED NOVEMBER 21, 2002. ACCEPTED IN FINAL FORM JANUARY 30, 2003. Reprint requests to: R. Wennberg, Division of Neurology, Toronto Western Hospital, 5W444, 399 Bathurst Street, Toronto, ON, Canada M5T 2S8. 
offer another route to obtain at least preliminary data that is not otherwise available. Published media injury reports appear to be very accurate, a finding attributed to the premise that the injuries suffered by professional athletes are but one additional aspect of the overall entertainment package of professional sport. ${ }^{2}$ Journalistic enterprise and a public demand for information will evidently conspire to uncover the nature of most injuries affecting public sports figures.

We examined the weekly media reports of injuries in the NHL from the 1986-87 season through the 2001-02 season to obtain data on the reported rate of concussions and to observe any changes which may have occurred over time.

\section{Methods}

All weekly injury reports published in The Hockey News for the 16 seasons 1986-87 through 2001-02 were reviewed for reported concussions. The Hockey News (www.thn.com, Transcontinental Publications, www.transcontinental-gtc.com) is a sports newspaper in publication since 1947, published weekly throughout the NHL season and 42 times per year. Weekly injury reports have been filed to The Hockey News by local team correspondents using a consistent technique over the duration of the study period. Each corresponding journalist submits the information contained in the weekly injury reports released by the NHL, which derive from reports submitted to the league by individual team public relations offices based on information from team physicians or trainers. The journalists are in continuous contact with the local team throughout the season and may also submit any individually uncovered injury information (Mr. S. McCaig, editor, The Hockey News, personal communication). With respect to concussions, there does not appear to be much difference between the final reports filed by journalists to The Hockey News and the numbers released by the NHL. For example, a comparison of the data published in The Hockey News with those released by the NHL in its weekly injury reports during the 1999-2000 and 2000-01 seasons (accessible through www.hockeyinjuries.com) showed nearly identical results: 62 concussions in 1999-2000 and 74 concussions in 2000-01 reported by The Hockey News, compared to 62 concussions in 1999-2000 (plus three head injuries without identified diagnosis and one case of vertigo) and 68 concussions in 2000-01 (plus four head injuries without identified diagnosis and five cases of headaches [2], dizziness [2] or vertigo [1]) reported by the NHL.

The injury report section of The Hockey News (published on a single page of the newspaper listing the injuries reported each week, separated by team) for all issues published over the study period was examined by the authors for reported concussions. The archived newspapers were made available for study, courtesy of the publisher. The injured players' names and teams were documented by the authors during data collection, but are not reproduced here. Consecutive weekly listings of the same player were considered to represent prolonged loss of action from a single concussion. A very few players in recent years were initially reported to be suffering from "migraine headaches," "dizziness," "concussion-type symptoms," or similar non-specific complaints. In The Hockey News data, these players invariably were later reported (in the injury reports of subsequent issues) to be injured with concussion, and their injuries were thus classified as concussions for this study.

The number of concussions was adjusted for changes in the number of teams and games per season over the 16-year study period, and expressed as: number of concussions per 1000 games.

Statistical analyses used the Chi-square test to look for differences between one season and the seasons preceding it, with a $\mathrm{p}$ value less than 0.05 considered significant.

Demographic data on yearly trends in player height and weight was obtained courtesy of the NHL Public Relations office.

A MEDLINE (1966 to August 2002) search for relevant articles was conducted using the search strategy ("brain injury", "concussion" or "head injury") and ("hockey").

\section{RESULTS}

The data per season are shown in the Table. The reported concussion rate during the last five years is more than triple that of the previous decade. Comparing each season with the prior season, significant increases in rate of concussions were reported in 1997-98 and 1998-99 ( $\mathrm{p}<0.05$ and 0.025 , respectively). The graph of reported concussion rate over time shows a sharp rise and subsequent plateau since 1997 (Figure). Given the appearance of the graph, Chi-square analysis was also performed on the data from the most recent six seasons, compared with the 10 seasons from 1986-87 through 1995-96, highlighting the difference in reported concussion rate from the 1996-97 season onward ( $\mathrm{p}<0.05$ for 1996-97, $\mathrm{p}<0.0005$ for the last four seasons).

To place the data in the context of the most commonly referred to variable theoretically impacting on risk of concussion, that is the ever increasing size of NHL players, the demographic data on player height and weight over the 16-year study period is presented in the Table and Figure. Mean player height increased by one inch and mean player weight increased by $10-11$ pounds over the 16 -year period.

\section{Discussion}

A predictable criticism and the major limitation of this study is that the data used were derived solely from the media. The veracity of the data may, therefore, be considered open to question, and subject to different criticisms such as: the injury reports submitted by team offices may not be accurate, for example, there may be intentional misreporting by individual teams to hide true injury information, or, the The Hockey News may not be consistent in its retrieval or reporting of injury information, even if the team injury reports are accurate. This may be true, to some extent, but there is no reason to believe $a$ priori that inaccuracies in these reporting systems could explain stable concussion rates for 10 seasons, followed by a tripling of the reported rate over two seasons and then stability once again at a new, higher rate for the next five seasons. That the reported changes may truly represent increased medical recognition is especially likely for a condition with evolving diagnostic criteria and no proven laboratory or imaging abnormalities, such as concussion.

A MEDLINE search revealed almost no relevant published data, from professional or amateur hockey, that address the 
Table: NHL average player size; number of teams, games, concussions per season

\begin{tabular}{|c|c|c|c|c|c|c|}
\hline Season & Height $^{1}$ & Weight $^{1}$ & Teams & Games $^{2}$ & Concussions $^{3}$ & Concussions/1000 games \\
\hline $86-87$ & $6^{\prime} 0^{\prime \prime}$ & 191 & 21 & 80 & 7 & 4 \\
\hline $87-88$ & $6^{\prime} 0^{\prime \prime}$ & 191.6 & 21 & 80 & 14 & 8 \\
\hline $88-89$ & $6^{\prime} 0^{\prime \prime}$ & 193 & 21 & 80 & 12 & 7 \\
\hline $90-91$ & 6'0" & 194.1 & 21 & 80 & 9 & 5 \\
\hline $91-92$ & $6^{\prime} 0^{\prime \prime}$ & 194.3 & 22 & 80 & 8 & 5 \\
\hline $92-93$ & $6^{\prime} 0^{\prime \prime}$ & 194 & 24 & 84 & 14 & 7 \\
\hline 94-95 & 6'1" & 196.4 & 26 & $48^{4}$ & 8 & 6 \\
\hline $95-96$ & 6'1" & 196.2 & 26 & 82 & 17 & 8 \\
\hline $96-97$ & 6'1" & 198.1 & 26 & 82 & 27 & $13^{*}$ \\
\hline $97-98$ & 6'1" & 200.2 & 26 & 82 & 43 & $20 *(p<0.05$ cf. $96-97)$ \\
\hline 98-99 & 6'1" & 201.1 & 27 & 82 & 67 & $30 *(\mathrm{p}<0.025$ cf. $97-98)$ \\
\hline $99-00$ & 6'1" & 199.3 & 28 & 82 & 62 & $27 *$ \\
\hline
\end{tabular}

${ }^{1}$ Data courtesy NHL Public Relations office

${ }^{2}$ Regular season schedule, per team

${ }^{3}$ As reported to The Hockey News

${ }^{4}$ Lockout-shortened season

*Significant increase compared with 10 season mean from 86-87 through 95-96 ( $\mathrm{p}<0.05$ for 96-97, $\mathrm{p}<0.0005$ for last five seasons)

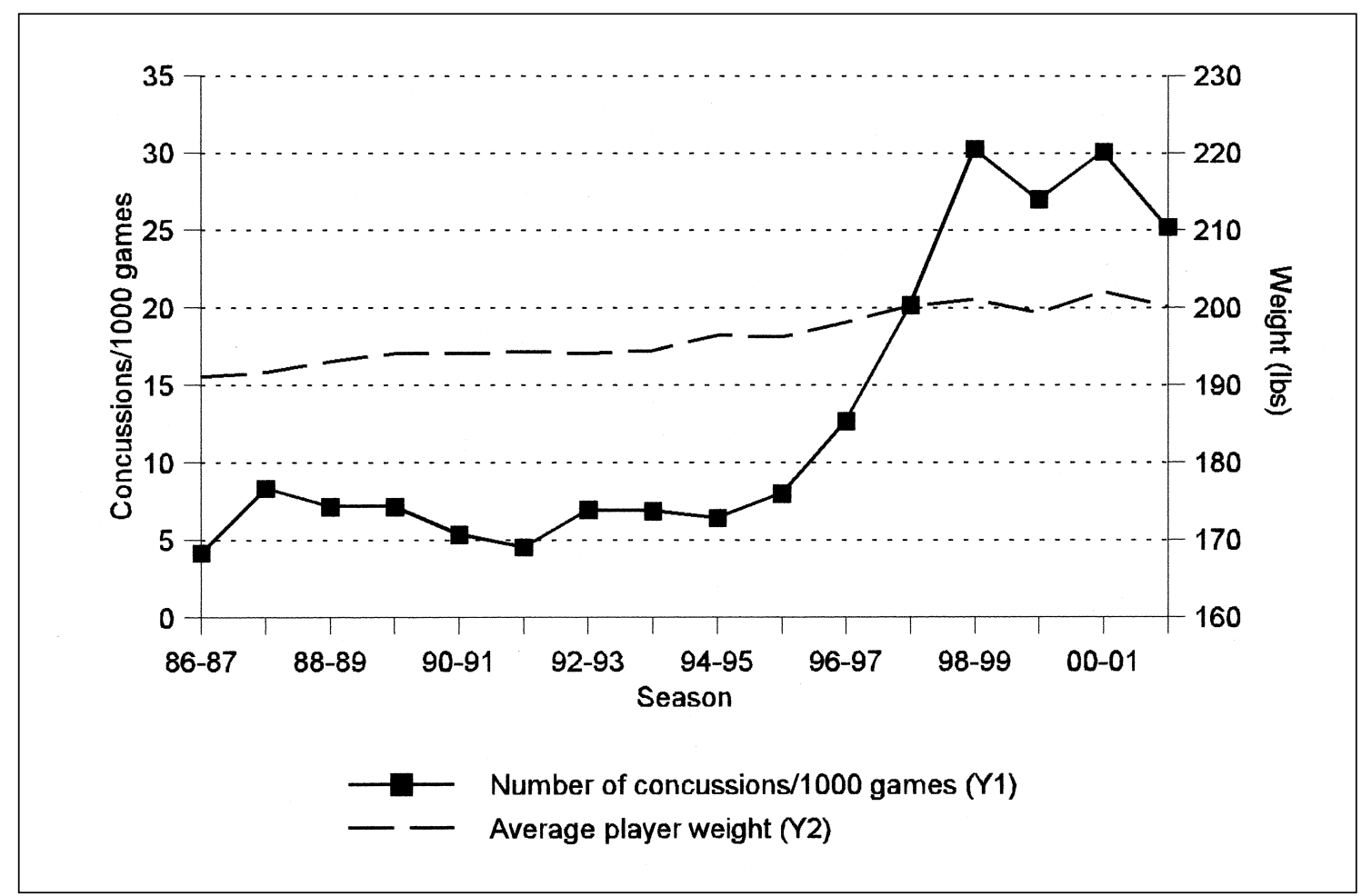

Figure: Concussions per season in the NHL, 1986-87 to 2001-02 (as reported by The Hockey News) 
question of whether or not concussions are increasing. Based on one prospective study, there would appear to have been no change in concussion frequency in the Swedish Elite League over four seasons from 1988-89 through 1991-92. ${ }^{3}$ A published review of injury statistics from a variety of professional and amateur teams, in North America and Europe, states in its summary that concussion frequency is increasing, but there are no data evident in the article to support that claim. ${ }^{4}$ In the same study, data from a single NHL team are described to show an increased injury rate from 1970 to 1990 , but this is stated to be proportional to the increased length of the professional hockey season. ${ }^{4}$ A recently published longitudinal study of injury rates affecting the German junior and senior national teams states in its abstract that concussions are increasing, although again no data are provided in the article to support that claim. ${ }^{5}$ However, recently presented data collected by a single team physician following the same Swedish Elite League team over the past 17 years does indicate an increase in concussions in recent years, ${ }^{6}$ with the team physician confident his diagnostic criteria have not changed (Dr. Y. Tegner, presentation to 1st International Symposium on Concussion in Sport, Vienna, 2001).

Nevertheless, at least for the NHL, the abrupt increase and subsequent plateau in concussions since 1996-97 suggests that increased recognition and reporting are primarily responsible for the apparent increase in incidence. Recent changes in the game (e.g. bigger, faster players, new equipment, harder boards and glass, etc.) have not occurred suddenly and, while theoretically increasing the risk of concussion, would have been expected to cause a correspondingly gradual increase in incidence.

It is interesting that the increase in reported concussions approximately coincided with: (a) commencement of the NHL Concussion Program in 1997, and (b) publication in 1997 of the American Academy of Neurology Practice Parameter on concussion in sports ${ }^{7}$ and an accompanying article outlining the diagnostic features of concussion. ${ }^{8}$ These initiatives represented the culmination of a series of steps taken by medical organizations, trainers and coaches to improve the medical identification of concussions, and reinforced that loss of consciousness is not a requirement for the diagnosis of concussion. All of this would seem to have appropriately increased the diagnosis of concussion and, at the same time, increased awareness of the scope of the problem with trainers, coaches, players and physicians, resulting in increased reporting.

Over the past decade, at least eight NHL players have retired prematurely because of repeated concussions and many more have been unable to play for extended periods because of postconcussion symptoms. ${ }^{9}$ To begin to better understand the nature of the problem, the league's concussion study program was conceived and, since 1997, baseline neuropsychological testing has been obtained for all NHL players, with repeat testing performed 24-48 hours after a concussion and further follow-up at five to seven days if necessary until symptoms resolve. Other variables under study include symptom scoring and grading systems, equipment (helmet type and mouthguard use), "environmental" factors (boards and glass), mechanisms of injury (through video analysis) and return to play timelines (a similar program is ongoing in the National Football League). ${ }^{1}$ In addition to the concussion study project, the NHL Injury Analysis Panel was created in 2000 to study safety issues related to rules enforcement, equipment and playing environment. Based on information gathered during the 2000-01 season, this panel recommended strict enforcement of existing rules to reduce deliberate blows to the head, correct adjustment and yearly replacement of certified helmets and changes to current shoulder and elbow pad designs whereby equipment manufacturers would cover exposed hard plastic surfaces with softer padding. The panel also recommended increased focus on "seamless" glass systems installed in some NHL rinks in recent years. These systems use a hardened glass which does not require traditional metal supports, improving fans' sightlines, but rendering the combination boards and glass more rigid than previous Plexiglas constructions. Technological advances have decreased the stiffness in new seamless glass systems and the NHL has mandated replacement of seamless glass in rinks where the construction is shown to be not sufficiently flexible.

Whether related to one or a combination of the above mentioned risk factors, or simply to the existence of bigger, faster players playing on rinks unchanged in size, it is possible that a small, true increase in the incidence of concussion in recent years might not have been identified in the present study, hidden beneath the abrupt, pronounced rise referable to increased reporting. Eventual formal publication of the ongoing prospective NHL data collection would be most informative in this regard.

\section{ACKNOWLEDGEMENTS}

The authors thank Susan Auld for meticulous assistance with data collection and Sam McCaig and The Hockey News for graciously allowing us to review their archives for this study.

\section{REFERENCES}

1. Meeuwisse W, Burke C. NHL concussion program. Br J Sports Med 2001;35:375 (abstract).

2. Orchard J. Who owns the information? Br J Sports Med 2002;36:16-18.

3. Tegner Y, Lorentzon R. Concussion among Swedish elite ice hockey players. Br J Sports Med 1996;30:251-255.

4. Biasca N, Simmen H-P, Bartolozzi AR, et al. Review of typical ice hockey injuries: survey of the North American NHL and Hockey Canada versus European leagues. Unfallchirurg 1995;98:283288.

5. Gröger A. Ten years of ice hockey-related-injuries in the German Ice Hockey Federation. Sportverl Sportschad 2001;15:82-86.

6. Tegner Y. Concussion experience: Swedish elite ice hockey league. Br J Sports Med 2001;35:376-377 (abstract).

7. Practice parameter: the management of concussion in sports (summary statement). Report of the Quality Standards Subcommittee. Neurology 1997;48:581-585.

8. Kelly JP, Rosenberg JH. Diagnosis and management of concussion in sports. Neurology 1997;48:575-580.

9. Greenberg J, Wilton P. Sports injuries and safety in the NHL. In: Diamond D, (Ed.) Total Hockey. The Official Encyclopedia of the National Hockey League. 2nd ed. Kingston, New York: Total Sports, 2000:578-580. 